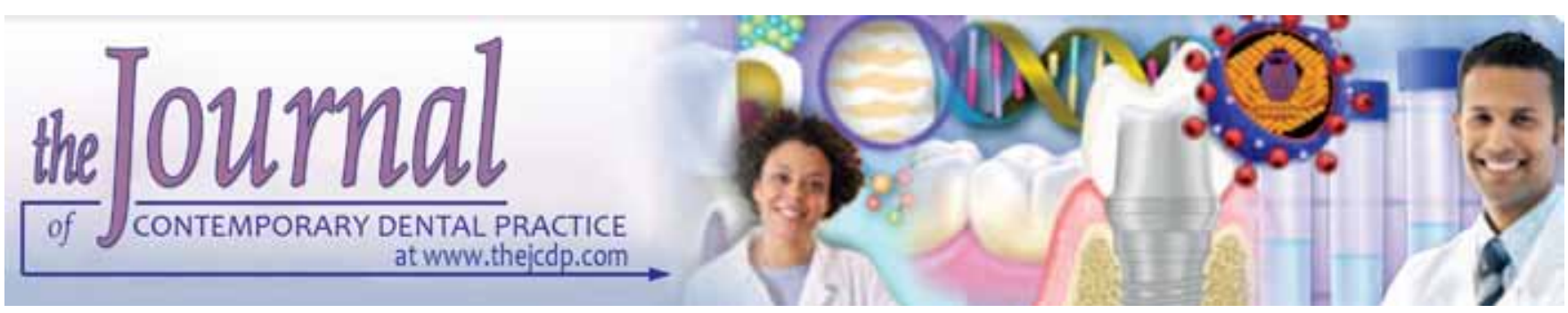

\title{
Ultrasound Effect in the Removal of Intraradicular Posts Cemented with Different Materials
}

\author{
${ }^{1}$ Fabio Luiz Camargo Vilella Berbert, ${ }^{2}$ Camila Galletti Espir, ${ }^{3}$ Fernando Simões Crisci \\ ${ }^{4}$ Marcelo Ferrarezzi de Andrade, ${ }^{5}$ Gisselle Moraima Chávez-Andrade, ${ }^{6}$ Renato de Toledo Leonardo \\ ${ }^{7}$ José Roberto Cury Saad, ${ }^{8}$ José Claudio Martins Segalla, ${ }^{9}$ Luiz Geraldo Vaz \\ ${ }^{10}$ Keren Cristina Fagundes Jordão Basso, ${ }^{11}$ Andrea Abi Rached Dantas
}

\begin{abstract}
Aim: This study evaluated the effect of ultrasonic vibration on the tensile strength required to remove intraradicular post cemented with different materials.

Materials and methods: Bovine teeth were selected, and $7 \mathrm{~mm}$ of the cervical root canals were prepared to size 5 Largo drill, the posts were cemented with zinc phosphate, Enforce (resin) or Rely X (glass ionomer). The specimens were divided into six groups $(n=10)$, according to the following procedures: $\mathrm{Gl}$-cementation with zinc phosphate associated with traction force; GII-cementation with zinc phosphate associated with ultrasonic activation and traction force; GIII-cementation with Enforce associated with traction force; GIV-cementation with Enforce associated with ultrasonic activation and traction force; GV-cementation with Rely X associated with traction force; and $\mathrm{GVI}$-cementation with Rely $\mathrm{X}$ associated with ultrasonic activation and traction force. The tensile test was conducted using the electromechanical testing machine, the force was determined by a specialized computer program and ultrasonic activation using the Jet Sonic Four Plus (Gnatus) device in 10P.
\end{abstract}

Results: Concerning to average ranking, GI showed statistically significant difference in comparison with GII and GVI $(p<0.05)$; there was no statistical difference in GIII and GIV when compared to other groups $(p>0.05)$.

\footnotetext{
1,2,4-7,10,11 Department of Restorative Dentistry, Araraquara Dental School, Universidade Estadual Paulista, Araraquara SP, Brazil

${ }^{3}$ Department of Health Sciences, Araraquara Dental School University Center of Araraquara, Araraquara, Brazil

${ }^{8,9}$ Department of Dental Materials and Prosthesis, Dental School, Universidade Estadual Paulista, Araraquara, Brazil
}

Corresponding Author: Fabio Luiz Camargo Vilella Berbert Assistant Professor, Department of Restorative Dentistry Araraquara Dental School, Rua Humaitá 1680, Centro CEP 14801-903, Araraquara, SP, Brazil, e-mail: fberbert@foar. unesp.br
Conclusion: The ultrasound favored the intraradicular post traction regardless of the employed cement in greater or lesser extent.

Clinical significance: The post removal is a routine practice in the dental office, therefore, new solutions and better alternatives are need to the practitioner. We did not find in the literature many articles referring to this practice. Thus, the results from this study are relevant in the case planning and to promote more treatment options.

Keywords: Dental cements, Tensile strength, Ultrasonics.

How to cite this article: Berbert FLCV, Espir CG, Crisci FS, de Andrade MF, Chávez-Andrade GM, de Toledo Leonardo R, Saad JRC, Segalla JCM, Vaz LG, Basso KCFJ, Dantas AAR. Ultrasound Effect in the Removal of Intraradicular Posts Cemented with Different Materials. J Contemp Dent Pract 2015;16(6):437-441.

Source of support: Nil

Conflict of interest: None

\section{INTRODUCTION}

Endodontic treatment is often performed on teeth with extreme loss of tooth structure and sometimes intraradicular posts are needed to provide sufficient retention and resistance for the final restoration or crown. ${ }^{1,2}$ The persistent microbiota in the root canal can lead to an unsuccessful endodontic treatment and to retreatment indication. The conservative orthograde retreatment is preferred to periradicular surgery. ${ }^{1}$ Sometimes the intraradicular post needs to be removed in the conservative retreatment ${ }^{3}$ and presents risks of fractures or root perforations, especially with loss dental structure. ${ }^{1,4}$ The chosen treatment of the post removal is based in the analysis of different aspects not involving only the intraradicular post, ${ }^{5,6}$ but the whole tooth, 
preserving the integrity of the dental remaining and periodontal ligament.

There are many techniques and devices to facilitate and promote a safer traction of the intraradicular post removal, such as rotary instruments, special forceps, hemostatic tweezers, special devices (Masserann Kit, Eggler post remover, the Ganon post remover, the Ruddle post removal), ultrasonic vibration or a combination of these. ${ }^{1,7-12}$

The instrumentation technique and irrigation solutions interfere in the post retention. ${ }^{13}$ Moreover, the type of cement influence the intraradicular retention, since the cement promote higher adhesion to the root walls and keep the post fixed. Currently four types of cementing agents are used to fix posts and to seal the irregularities between the post and the canal walls: zinc phosphate, zinc polycarboxylate, glass ionomer and resin cements. ${ }^{1,14,15}$ Glass ionomer and resin cements are largely employed in the intraradicular postcementation due to its adhesive properties. Recently, bioactive materials are also been used in several fields of dentistry. ${ }^{16}$ Ceramir, e.g. can be used as a luting agent, working with the same principle of calcium aluminate and glass ionomer cement. ${ }^{17}$

Rely-X is dual-cure glass ionomer cement, self-adhesive and has been compared with different cements. ${ }^{18-20}$ Enforce is resin cement presenting dual-setting time that have been studied and evaluated. ${ }^{21,22}$ So, when the post-traction is needed, the cement adhesive properties should be considered, ${ }^{18}$ since it can lead to more or less difficulty in the post removal.

Thus, the aim of this study was to evaluate the effect of different cements and the association of cementation line wear and ultrasonic vibration applied on the cementation line of different cements during the intraradicular posttraction.

\section{MATERIALS AND METHODS}

Sixty extracted bovine teeth were stored in $10 \%$ formaldehyde solution for 24 hours and then kept in saline solution until the beginning of the research. The teeth were sectioned at the cervical level, the seven cervical millimeter of each specimen were prepared to size 5 Largo drill. Then, the roots were randomly divided into six groups $(\mathrm{n}=10)$ shown in Table 1.

The roots were embedded in polyester resin cylinders (Resina Poliester MIL-ASA, Milflex Indústrias Químicas Ltda., São Bernardo do Campo, SP, Brazil) and submitted to tensile testing using eletromechanical machine (Material Test System-MTS 810). Metallic post had a perforation in its head portion and a 07 orthodontic wire pierced it at the eletromechanical machine.
Table 1: Distribution of groups according to the post removal techniques

\begin{tabular}{llll}
\hline Groups & $n$ & Cement & Technique \\
\hline I & 10 & Zinc phosphate & Traction \\
II & 10 & Zinc phosphate & Wear, ultrasound and traction \\
III & 10 & Enforce & Traction \\
IV & 10 & Enforce & Wear, ultrasound and traction \\
V & 10 & Rely X & Traction \\
VI & 10 & Rely X & Wear, ultrasound and traction \\
\hline
\end{tabular}

Each material was handled according to the manufacturer's recommendations. During the cement setting time, $5 \mathrm{~kg}$ weight was applied to the long axis of the post for 4 minutes. After 15 minutes, the specimens were stored in water and kept at $37^{\circ} \mathrm{C}$ for 24 hours. Each group was prepared to the tensile testing as the following treatments: GI and GII—zinc phosphate (SSW Artigos Dentários Ltda., Rio de Janeiro, RJ, Brazil) was handled according to the manufacturer's recommendations, GIII and GIVenforce with fluoride, resin cement (Dentsply Indústria e Comécio Ltda., Brasil, Petrópolis, RJ, Brazil), was handled according to the manufacturer's recommendations. Before cementation, the root canal was acid etched for 15 seconds, rinsed with water for 10 seconds, dried using air-spray for 2 seconds and the excess was removed with absorbent paper points. The Prime and Bond 2.1 (Single Bond) adhesive system was applied and light cured for 10 seconds; the cement preparation (paste/paste) was carried out in equal amounts of base and catalyst paste and mixed for 20 seconds. The cement was inserted into the root canal, then the post was placed into the canal and light cured for 30 seconds in the buccal, lingual, mesial and distal faces, and GV and GVI-Rely X, glass ionomer cement (3M) was handled according to the manufacturer's recommendations. Before cementation, the root canal was etched for 15 seconds, rinsed with water for 10 seconds, dried using air-spray for 2 seconds, and the excess was removed with absorbent paper points. The Prime and Bond '2.1 (Single Bond) adhesive system was applied and light cured for 10 seconds. The cement preparation (powder/liquid) was in the 1:1 ratio (3 powder scoops for 3 liquid drops) mixed at the glass plate for 10 seconds. The cement was inserted into the root canal, the post was placed into the canal and light cured for 40 seconds in the oclusal faces.

In GI, the metallic cores were cemented with zinc phosphate and subjected to traction (Fig. 1D), GII, the metallic cores were cemented with zinc phosphate and submitted to wear in the cementation line about $1 \mathrm{~mm}$ depth around the post using a $\mathrm{n}^{\circ} 2200$ diamond bur (KG Sorensen Ind Com Ltda., Barueri, SP, Brazil) at high speed handpiece (Fig. 1A), and $3 \mathrm{~mm}$ depth using 'long neck' bur (Maillefer, Ballaigues, Switzerland) at low speed 

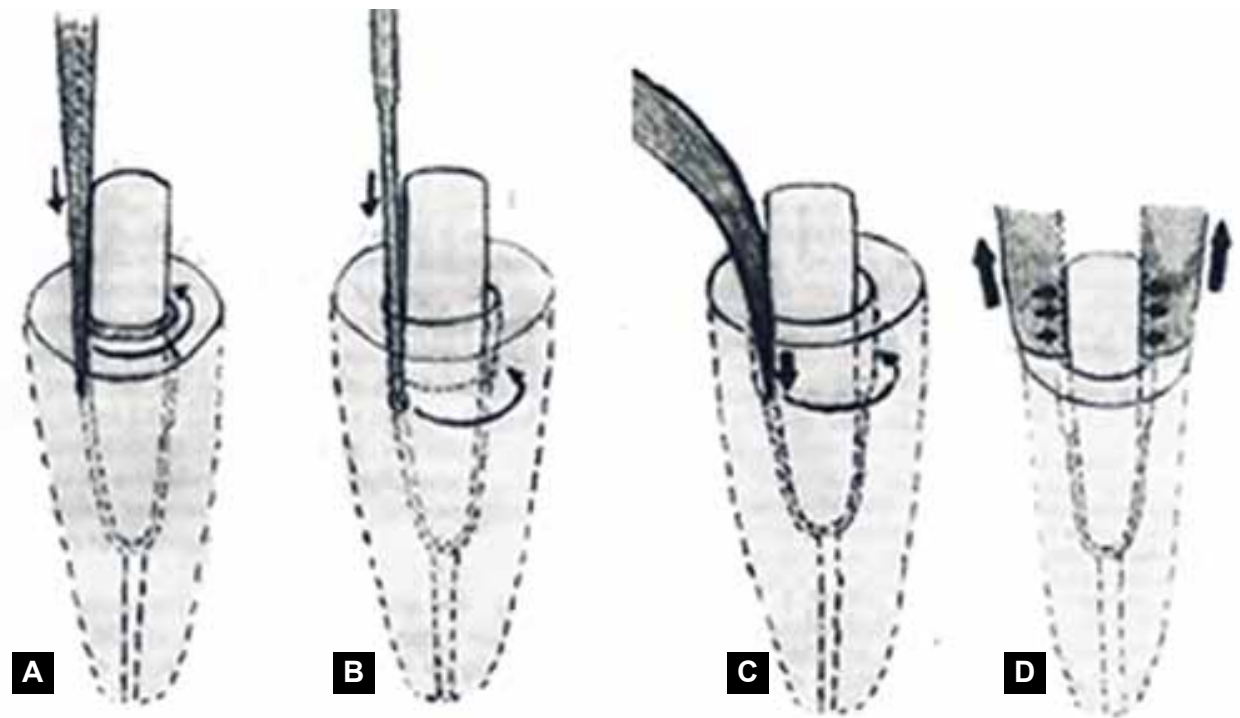

Figs $1 A$ to D: Sequence of the cast metallic core removal and the cementation line wear using the 'pencil tip' diamond bur (a) deep wear using the LN bur (b) ultrasonic application in the cementation line (c) and the traction (d)

(Fig. 1B). Then, the specimens were subjected to ultrasonic vibration (Jet Sonic Four Plus, Gnatus), in periodontics $10 \mathrm{P}$, using the periodontics tip number 2 within the gap created in the cementation line wear, for 120 seconds (30 seconds in the buccal, mesial, lingual and distal faces) under copious irrigation with distilled water (Fig. 1C). The specimens were submitted to traction (Fig. 1D), in GIII, the metallic cores were cemented with Rely $X$ glass ionomer and subject to traction (Fig. 1D), in GIV, the metallic cores were cemented with Rely $\mathrm{X}$ glass ionomer and subject to wear in the cementation line about $1 \mathrm{~mm}$ depth around the post using a $\mathrm{n}^{\mathrm{O}} 2200$ diamond bur (KG Sorensen Ind Com Ltda., Barueri, SP, Brazil) at high speed handpiece (Fig. 1A), and $3 \mathrm{~mm}$ depth using 'Long Neck' bur (Maillefer, Ballaigues, Switzerland) at low speed (Fig. 1B). Then, the specimens were subjected to ultrasonic vibration (Jet Sonic Four Plus, Gnatus), in periodontics 10P, using the periodontics tip number 2 within the gap created in the cementation line wear, for 120 seconds (30 seconds in the buccal, mesial, lingual and distal faces) under copious irrigation with distilled water (Fig. 1C). The specimens were submitted to traction (Fig. 1D), in GV, the metallic cores were cemented with Enforce resin cement and subjected to traction (Fig. 1D), in GVI, the metallic cores were cemented with Enforce resin cement and submitted to wear around the cementation line about $1 \mathrm{~mm}$ depth using a $\mathrm{n}^{\mathrm{O}} 2200$ diamond bur (KG Sorensen Ind Com Ltda., Barueri, SP, Brazil) at high speed handpiece (Fig. 1A), and $3 \mathrm{~mm}$ depth using 'long neck' bur (Maillefer, Ballaigues, Switzerland) at low speed (Fig. 1B). Then, the specimens were submitted to ultrasonic vibration (Jet Sonic Four Plus, Gnatus), in periodontics 10P, using the periodontics tip number 2 within the gap, that was created in the cementation line wear, for 120 seconds (30 seconds in the buccal, mesial, lingual and distal faces) under copious irrigation with distilled water (Fig. 1C). The specimens were submitted to traction (Fig. 1D).

The specimens were submitted to tensile strength test using the electromechanical testing machine (Material Test System-MTS 810). The force required to traction force similar to the clinical situation (Fig. 1D) and data were analyzed using the Test Works program for Test Star II system. The load cell used was $1 \mathrm{kN}$ and the speed was $1 \mathrm{~mm} /$ minute. The results among experimental groups are shown two by two using Newman-Keuls test with $5 \%$ significance level.

\section{RESULTS}

The ultrasound application time (with no traction associated) and the tensile strength required for the post removal determined the ranking for each specimen, the rank sum was calculated for each group and the data were submitted to statistical tests.

The ordering of the experimental groups from most to least efficient in the intraradicular post removal according to the average ranking is shown in Table 2.

Concerning to average ranking, GI showed statistically significant difference in comparison with GII and GVI $(p<0.05)$; there was no statistical difference in GIII and GIV when compared to other groups ( $p>0.05)$.

\section{DISCUSSION}

Dentin posts are mechanically inserted into the prepared cavity to support and maintain the final restoration. Attin et al compared the fracture resistance of glued restorations $v s$ those using posts and they observed 
Table 2: Experimental groups ordered from most to least efficient in the intraradicular removal according to the average ranking

\begin{tabular}{llll}
\hline Groups & $\begin{array}{l}\text { Efficiency order } \\
\text { (tensile strength) }\end{array}$ & Rank sum & $\begin{array}{l}\text { Average } \\
\text { ranking }\end{array}$ \\
\hline GI & $5(128.01)$ & 407 & $40.7^{\mathrm{a}, \mathrm{d}}$ \\
GII & $2(69.92)$ & 220 & $22.0^{\mathrm{b}}$ \\
GIII & $4(103.48)$ & 315 & $31.5^{\mathrm{a}, \mathrm{b}, \mathrm{d}}$ \\
GIV & $3(91.28)$ & 269 & $26.9^{\mathrm{a}, \mathrm{b}, \mathrm{c}}$ \\
GV & $6(139.54)$ & 429 & $42.9^{\mathrm{a}, \mathrm{d}}$ \\
GVI & $1(60.69)$ & 190 & $19.0^{\mathrm{b}, \mathrm{c}}$ \\
\hline
\end{tabular}

$\mathrm{a,b,c,d}$ Different letters indicate statistically significant difference on the same column $(p<0.05)$.

that the fracture resistance was higher when the posts were employed. ${ }^{23}$ This is a practical and conservative resolution for large restorations. Thus, the use of posts presents a usually practice that promotes more lasting success of the final restoration.

In the cases of intraradicular post removal, the dental structure condition must be considered especially when an endodontic treatment was performed due to the remaining structure is more fragile and susceptible to fracture. Moreover, there is a consensus that worn teeth can be a result from a combination of long-lasting etiological factors, which increases the teeth wear over de the years. ${ }^{24,25}$ Thus, a correct diagnosis and treatment planning should be carefully planned to avoid further dental damage.

Recently, Marques et al examined the influence of the instrumentation technique and irrigating solutions on the bond strength of the glass fiber posts to radicular dentin. The specimens were submitted to tensile test at a constant speed of $1.0 \mathrm{~mm} /$ minute and load 2,000 Kgf comparing manual and rotary instrumentation and irrigation with $2.5 \%$ hypochlorite and $2 \%$ chlorhexidine. The authors concluded that irrigation with $2.5 \%$ hypochlorite presented a negative effect on the posts mechanical retention in both instrumentations. ${ }^{13}$ Thus, the difficulty in the posts removal can be associated to several factors and is facilitated using effective devices.

Among the types of posts, the cast metallic core, ${ }^{7}$ prefabricated, ${ }^{1}$ direct bond retention ${ }^{26}$ or glass fiber post ${ }^{13}$ are available options to the treatment. The cast metallic post was chosen due to it is more suitable to the bovine tooth dimensions after a standardized preparation of root canals as described above.

The intraradicular post removal using ultrasound promoted greater safety and preservation of the remaining dental structure during this procedure. Berbert et al had proven the effectiveness of ultrasonic vibration even when magnetostrictive devices (Profi-Endo) were used. The application for 2 minutes decreased about $30 \%$ of the required force for the displacement of prosthetic core cemented with zinc phosphate cement. ${ }^{14}$
On the other hand, ${ }^{27}$ analyzed whether metal type, cement type and the use of ultrasonic vibration influence the amount of tensile force required to remove parallelsided, prefabricated, metal posts from tooth roots. In this in vitro experiment, metal type, cement type and ultrasonic vibration did not influence the force required to remove posts.

Berbert et al evaluated the effect of ultrasonic application in the intraradicular post removal on the head portion of intraradicular post and in the cementation line, both situations were associated to cementation line wear around the post, and the standard depth was 3 millimeters. ${ }^{7}$ Situations, such as the ultrasonic application on the head portion of the post, with no cementation line wear or only the cementation line wear were also evaluated. All these situations preceded the core traction, the tensile strength required to the post displacement was quantified, and the control group was only subjected to traction with no prior preparation. The authors concluded that the cementation line wear associated with ultrasound application in the cementation line before the traction was significantly more effective than only traction, the cementation line wear, the ultrasound application on the post head portion and cementation line wear associated with ultrasound application in the cementation line of the post head portion techniques before the traction.

The present study evaluated the ultrasonic application on different cementing agents according to the protocol recommended by Berbert et al. ${ }^{7}$ The results showed that all cements were affected by the ultrasonic application before the traction and the required tensile strength for the intraradicular post removal was significant statistically decreased, except for Rely X that presented no significant statistical result.

All experimental groups that were not subjected to ultrasonic application presented similar mean strength required for the intraradicular post displacement, regardless the kind of cement. The groups that were subjected the ultrasonic application also presented similar average ratios of tensile strength.

\section{CONCLUSION}

This study concludes that all cements were affected by ultrasonic application and had the traction of the intraradicular post facilitated. Further studies should be conducted to supplement these data and improve this procedure.

\section{CLINICAL SIGNIFICANCE}

The post removal is a routine practice in the dental office, therefore, new solutions and better alternatives are need 
to the practitioner. We did not find in the literature many recent articles referring to this procedure. Thus, the results from this study are relevant in the case planning and to promote more treatment options.

\section{REFERENCES}

1. Karova E, Topalova-Pirinska S. Comparison of the time required for ultrasonic removal of prefabricated intraradicular posts. J of IMAB 2013;19:426-429.

2. Gonzaga CC, de Campos EA, Barato-Filho F. Restoration of endodontically treated teeth. RSBO 2011;8:33-46.

3. Allgayer S, Vanni JR. Intraradicular post and core removal followed by endodontic retreatment: 13-year follow-up. RSBO 2011;8:99-104.

4. Radeva EN. Removal of metal posts in retreatment of teeth with failed endodontic treatment (clinical cases). Int J Sci Res 2015;4:2084-2088.

5. Figueiredo FE, Martins-Filho PR, Faria ESAL. Do metal post-retained restorations result in more root fractures than fiber post-retained restorations? A systematic review and meta-analysis. J Endod 2015;41:309-316.

6. Peciuliene V, Rimkuviene J, Maneliene R, Pletkus R. Factors influencing the removal of posts. Stomatologija 2005;7:21-23.

7. Berbert FLCV, Crisci FS, Berbert A, Bonetti-Filho I, Vaz LG. Efeito do desgaste da linha de cimento, da vibração ultrasônica e da associação de ambas sobre a força de tração empregada na remoção de pinos intra radiculares. Rev Odontol UNESP 2002;31:205-229.

8. Williams VD, Bjorndal AM. The Masserann technique for the removal of fractured posts in endodontically treated teeth. J Prosthet Dent 1983;49:46-48.

9. Machtou P, Sarfati P, Cohen AG. Post removal prior to retreatment. J Endod 1989;15:552-554.

10. Buoncristiani J, Seto BG, Caputo AA. Evaluation of ultrasonic and sonic instruments for intraradicular post removal. J Endod 1994;20:486-489.

11. Stamos DE, Gutmann JL. Survey of endodontic retreatment methods used to remove intraradicular posts. J Endod 1993;19:366-369.

12. Ruddle CJ. Nonsurgical retreatment. J Endod 2004;30:827-845.

13. Marques EF, Bueno CE, Veloso HH, Almeida G, Pinheiro SL. Influence of instrumentation techniques and irrigating solutions on bond strength of glass fiber posts to root dentin. Gen Dent 2014;62:50-53.

14. Berbert A, Filho MT, Ueno AH, Bramante CM, Ishikiriama A. The influence of ultrasound in removing intraradicular posts. Int Endod J 1995;28:54-56.
15. Adarsha MS, Lata DA. Influence of ultrasound, with and without water spray cooling, on removal of posts cemented with resin or glass ionomer cements: an in-vitro study. J Conserv Dent 2010;13:119-123.

16. Snehal Sonarkar, Rucheet Purba, 'Bioactive materials in conservative dentistry,' Int J Contemp Dent Med Rev, vol. 2015. Article ID: 340115, 2015. DOI: 10.15713/ins.ijcdmr.47

17. Jefferies S. Bioactive and biomimetic restorative materials: a comprehensive review_Part II. J Esthet Restor Dent 2014;26: 27-39.

18. Aleisa K, Alghabban R, Alwazzan K, Morgano SM. Effect of three endodontic sealers on the bond strength of prefabricated fiber posts luted with three resin cements. J Prosthet Dent 2012;107:322-326.

19. Goracci C, Tavares AU, Fabianelli A, Monticelli F, Raffaelli O, Cardoso PC, Tay F, Ferrari M. The adhesion between fiber posts and root canal walls: comparison between microtensile and push-out bond strength measurements. Eur J Oral Sci 2004;112:353-361.

20. Pereira JR, Neto Tde M, Porto Vde C, Pegoraro LF, do Valle $\mathrm{AL}$. Influence of the remaining coronal structure on the resistance of teeth with intraradicular retainer. Braz Dent J 2005;16:197-201.

21. Faria-e-Silva A, Boaro L, Braga R, Piva E, Arias V, Martins L. Effect of immediate or delayed light activation on curing kinetics and shrinkage stress of dual-cure resin cements. Oper Dent 2011;36:196-204.

22. Ortega VL, Pegoraro LF, Conti PC, do Valle AL, Bonfante G. Evaluation of fracture resistance of endodontically treated maxillary premolars, restored with ceromer or heat-pressed ceramic inlays and fixed with dual-resin cements. J Oral Rehabil 2004;31:393-397.

23. Attin T, Hellwig E, Hilgers RD, Zimmermann U. Fracture toughness of pin-retained class 4 restorations. Oper Dent 1994;19:110-115.

24. Moslehifard E, Nikzad S, Geraminpanah F, Mahboub F. Fullmouth rehabilitation of a patient with severely worn dentition and uneven occlusal plane: a clinical report. J Prosthodont 2012;21:56-64.

25. Van't Spijker A, Rodriguez JM, Kreulen CM, Bronkhorst EM, Bartlett DW, Creugers NH. Prevalence of tooth wear in adults. Int J Prosthodont 2009;22:35-42.

26. de Andrade CL, Goncalves TM, Santos IL, Barros MS, Araujo NR, Cury AA. Direct adhesive pin-retained restorations for severely worn dentition treatment: a 1.5-year follow-up report. Braz Dent J 2014;25:357-362.

27. Hauman $\mathrm{CH}$, Chandler NP, Purton DG. Factors influencing the removal of posts. Int Endod J 2003;36:687-690. 